\title{
Mobiliário urbano e vandalismo: tópicos para pensar o design
}

\section{Urban furniture and vandalism: topics to think about design}

Fernando Araújo Costa, Universidade Federal de Juiz de Fora

fernando.costa@arquitetura.ufjf.br

Karine Dias de Jesus, Universidade Federal de Juiz de Fora

karinediasj@hotmail.com

Antonio Ferreira Colchete Filho, Universidade Federal de Juiz de Fora

arqfilho2@globo.com

\begin{abstract}
Resumo
Espaço público e mobiliário urbano têm uma relação de interdependência importante que nos ajuda a compreender muitas manifestações da vida cotidiana. A partir de diferentes atos considerados vandalismo, o presente estudo destaca ações praticadas sobre mobiliários urbanos, com o objetivo de analisar as relações estabelecidas entre usuário e espaço, além de evidenciar o papel ativo do design do mobiliário urbano na condução dessa interação. Por meio de revisão de literatura, são apresentados tanto aspectos envolvidos na depredação, como ações que visam a melhor conservação do mobiliário, através de atributos de projeto. Conclui-se que, da estreita relação entre os conflitos sócio-culturais urbanos e a depredação dos espaços públicos, o design pode atuar positivamente, quando, em seu processo criativo, há a incorporação de complexidades de natureza transdisciplinar, voltadas para que a dinâmica objeto-espaço contribua para a promoção de espaços públicos mais integrados.
\end{abstract}

Palavras-chave: Mobiliário urbano, Vandalismo, Espaço público.

\begin{abstract}
Public space and urban furniture have an important interdependence relationship that helps us understand many manifestations of everyday life. Based on different acts considered vandalism, this study highlights actions taken on urban furniture, with the aim of analyzing the relationships established between user and space, in addition to highlighting the active role of urban furniture design in conducting this interaction. Through a literature review, both aspects involved in depredation and actions aimed at better furniture conservation are presented, through design attributes. It is concluded that, from the close relationship between urban sociocultural conflicts and the depredation of public spaces, design can act positively when, in its creative process, there is the incorporation of transdisciplinary complexities, aimed at the dynamic object-space contributes to the promotion of more integrated public spaces.
\end{abstract}

Keywords: Urban furniture, Vandalism, Public space. 


\section{Introdução}

Diante das complexas relações estabelecidas entre transeuntes e o espaço público da cidade contemporânea, um olhar sobre o vandalismo como marca latente dessas dinâmicas apresenta uma interessante perspectiva. Constantemente, elementos, como abrigos de transporte público, caixas coletoras de lixo, placas de sinalização, cabines telefônicas públicas e equipamentos esportivos são alvos tanto da depredação ativa quanto do mau uso, intencionalmente ou não. Tais atos são tipificados como crime, conforme o Código Penal, Lei $\mathrm{N}^{\circ} 2.848 / 40$, que, diante da destruição do patrimônio público, submete o infrator à pena de detenção de seis meses a três anos e multa, além da pena correspondente à violência. No entanto, apesar desse aspecto legal, observa-se frequentemente a marca deixada pela depredação em diversos espaços públicos das cidades.

Estes atos de vandalismo podem ser compreendidos através da psicologia ambiental, ou seja, do estudo do indivíduo em seu contexto. Este campo de estudo possui como tema central as inter-relações - indo além das relações somente - entre a pessoa e o meio ambiente físico e social, uma vez que as dimensões sociais e culturais se fazem sempre presentes na definição dos ambientes, mediando a percepção, avaliação e as ações do indivíduo. Sob essa perspectiva, nota-se que cada indivíduo apresentará sua própria compreensão do ambiente físico e social e, assim, tal inter-relação também abrange os efeitos que cada ambiente físico tem sob as condutas humanas, de modo que exista uma reciprocidade entre pessoa e ambiente (MOSER, 1998).

Os mobiliários urbanos, exemplares de arte pública ou objetos arquitetônicos, tornam-se suscetíveis à contestação e ao vandalismo, por sua disposição - os espaços públicos -, mas também pela relação que estabelece ou não com seus usuários - pelos termos de Correia (2015, p. 81), "um público eclético, heterogêneo, não advertido, não sensibilizado, não familiarizado, não favorável, e sobretudo muito reativo". Montenegro (2013, p. 106) indica que o usuário estabelece uma relação mais intensa e duradoura com os mobiliários, ao passo que a ideia de conjunto e coerência demonstra-se evidente, o que leva os indivíduos a interagirem de forma mais efetiva com tais objetos. Ou seja, compreende-se "funções atribuídas àqueles produtos, provocando reações sensoriais, psicológicas e emocionais, que facilitam a interface homemproduto-ambiente". Montenegro (2013, p. 97) argumenta:

O mobiliário urbano, como um bem público, deve atender às demandas sociais dos cidadãos por serviços públicos que lhes proporcione facilidade de uso e acesso, segurança, conforto e bem-estar. Quando esses aspectos são negligenciados, seja do ponto de vista do design ou da gestão pública, os elementos sofrem rápido desgaste pelo abandono e falta de manutenção, vandalismo e destruição já que, funcionalmente, esteticamente e simbolicamente, não atendem às expectativas de seus usuários.

Por efeito da problemática da depredação de mobiliários urbanos, as municipalidades buscam, através de políticas públicas, o combate e a conscientização a respeito dessas práticas. Muitas vezes, os próprios equipamentos atuam como suporte às campanhas, por configurarem um apoio de baixo custo e larga veiculação. Além disso, atualmente, empresas buscam, através do design, produzir mobiliários com características antivandalismo, como forma de diminuir a vulnerabilidade, em alguns itens ou no todo, de um determinado mobiliário urbano. 
A partir dessa breve contextualização e com metodologia pautada em revisão de literatura, este artigo analisa o vandalismo como prática recorrente nas cidades contemporâneas, enfatizando a depredação sofrida pelos mobiliários urbanos implantados nos espaços públicos e os desdobramentos de tal ação para as cidades com alto custo social. Por fim, analisam-se insumos para projetos de mobiliários que busquem alternativas à presente problemática do vandalismo, que agreguem mais qualidade e melhor performance para o campo do design tanto do próprio mobiliário, quanto do espaço onde estes são implantados.

\section{Vandalismo em termos gerais}

Historicamente, os termos "vândalos" e "vandalismo" surgem de atos destrutivos contra "bens materiais de valor patrimonial e cultural". O primeiro advém da referência ao povo de origem germânica oriental que, tendo participado das invasões bárbaras, se destacou pelo intenso movimento de devastação e saques; o segundo foi cunhado pelo abade Henri Grégoire, no século XVIII, em oposição aos danos sobre o patrimônio artístico do Antigo Regime, devido à atuação de parcelas da armada republicana (CORREIA, 2015, p. 77). Este autor contribui com a conceituação de vandalismo, ao enxergá-lo como ato que "consiste em destruir, degradar, deteriorar, voluntariamente, o bem de outrem, seja um bem público, ou um bem privado". Apesar de referir-se a monumentos e obras de arte, entende-se, por extensão, que todo e qualquer tipo de elemento disposto nos espaços públicos estão sujeitos a atos tais como "pintar, riscar, cortar, partir, pôr ácido, incendiar, bombardear, atirar objetos, roubo de partes" ou de sua totalidade (CORREIA, 2015, p. 79).

Segundo Bostani (2017), um dos aspectos mais importantes relacionados ao vandalismo é que, diferentemente dos antigos vândalos, que destruíam as terras de outros ou algo feito por outros povos, os "vândalos modernos" destroem algo que pertence à sua própria sociedade, isto é, suas perdas voltam para eles mesmo, ainda que eles não possuam consciência desse fato. Salienta-se, portanto, que nenhum indivíduo deve optar pelo caminho da depredação, independentemente de suas origens, grupo ou classe social.

Através da compreensão do vandalismo como processo comportamental heterogêneo, Moser (1992, p. 52) indica que este termo abrange "comportamentos para os quais as motivações são extremamente diferentes". Outro ponto importante, apresentado pelo autor, é o peso do consenso social diante dessas ações, de forma que "a maioria das definições de vandalismo nada mais são do que expressões de senso comum". Prossegue afirmando que a genérica definição do vandalismo como "dilapidação ou destruição de um objeto ambiental" desconsidera qualquer referência à motivação do vândalo, ao aceitar, por exemplo, que este último não pode ser conhecido. Desse modo, o pesquisador conclui que a avaliação de um ato de vandalismo está intimamente ligada à perspectiva do observador, havendo três abordagens possíveis: a concentração sobre o dano, sobre o autor ou sobre o contexto. Moser ainda indica que o julgamento sobre se tal ato se configura ou não como vandalismo depende de seu resultado. $\mathrm{Ou}$ seja, "para que a dilapidação de qualquer objeto seja qualificada como vandalismo, é 
indispensável a intervenção de um julgamento de valor", sendo esse julgamento produzido pela vítima do ato, em conjunto ao prejuízo causado (MOSER, 1992, p. 52).

Cabe ressaltar que o vandalismo é uma questão a ser tratada no âmbito social. Cohen (1984) reflete sobre as diferentes percepções que o vandalismo pode produzir, uma vez que sua apreensão determina a maneira pela qual tal fenômeno será discutido, seja na mídia, na opinião pública, nos sistemas de controle ou nas teorias empregadas pelos próprios cientistas sociais. Dessa maneira, o autor sublinha que esses grupos não são "apenas públicos passivos, mas participantes ativos no drama do vandalismo: tomam decisões fatídicas, influenciam a coleta de estatísticas e são responsáveis por traçar prioridades" (COHEN, 1984, p. 231). Em suma, determinam onde e como o vandalismo é colocado na agenda pública de qualquer sociedade.

As motivações para que um indivíduo ou grupo vandalize podem ser variadas. A partir da leitura de Allen (1984), Baron e Fisher (1984), Canter (1984), Cohen (1984) e Moser (1992), Cruz (2018, p. 20-29) sintetiza uma série de possíveis estímulos ao vandalismo: pelo prazer de produzir efeitos negativos; para satisfazer algum sentimento de frustração; compensar o aborrecimento; atingir algum objetivo; exprimir opinião, arte ou identidade; necessidade de satisfazer a curiosidade e explorar os limites; responder a injustiças que acreditem ter sofrido; sentir excitação ou apreciar a beleza que pode resultar da destruição. A autora ainda ressalta que o ato vai muito além do contexto do espaço onde ocorre, por vezes até desassociando-se do objeto que fora destruído ou danificado e se concentrando apenas nas razões mais profundas e abrangentes que o impulsionaram.

O vandalismo, como ato que visa à depredação do patrimônio público ou privado, é uma prática que se realiza há tempos na história. Suas motivações variam, bem como o entendimento sobre o que leva determinada ação ser considerada como tal. $O$ indivíduo, o ambiente e o objeto alvo são três aspectos que, dentro do contexto social, indubitavelmente devem ser levados em consideração em estudos e projetos que evidenciam esta temática. Dessa maneira, a investigação sobre os mobiliários urbanos, sua inserção nesta tríade e a importância do contexto social se justificam, visto que estão altamente suscetíveis à prática do vandalismo, devido ao seu contato constante e direto com o público.

\section{Relações sociais nos espaços públicos e a depredação do mobiliário urbano}

A pluralidade, intrínseca aos espaços públicos, advém de uma série de atividades e usos praticados por grupos sociais, quase sempre bastantes heterogêneos. É comum afirmar que lugares tidos como perigosos na maioria das vezes são aqueles onde as características de abandono, ausência de infraestrutura ou de manutenção são predominantes. Contudo, tais locais não são os únicos a serem alvo de vandalismo, ainda que haja maior número de ocorrências.

Um experimento realizado na década de 1960 pelo psicólogo Philip Zimbardo pode ser utilizado na construção de um paralelo que ajuda a compreender as ações de vandalismo sobre veículos presentes em espaços públicos com características distintas. Em 1969, Zimbardo dispôs dois veículos do mesmo modelo em duas áreas da cidade de Nova York, uma rica e tranquila, 
Palo Alto, outra pobre e conflituosa, o Bronx. Na segunda, rapidamente houve vandalismo sobre o veículo, enquanto, na primeira, o automóvel manteve-se intacto até os investigadores, após uma semana, quebrarem uma de suas janelas, desencadeando rapidamente o mesmo processo ocorrido no Bronx. O resultado do experimento consiste no entendimento de que elementos que apresentem algum indício de descuido ou degradação são mais suscetíveis ao vandalismo (ODON, 2016). O experimento levou o cientista político James Wilson e o psicólogo criminologista George Kelling a um estudo, publicado na revista The Atlantic. Kelling e Wilson (1982) explicam:

A propriedade indesejada torna-se um jogo justo para as pessoas que querem se divertir ou saquear e até mesmo para as pessoas que normalmente não sonham em fazer essas coisas e que provavelmente se consideram cumpridoras da lei. Por causa da natureza da vida comunitária no Bronx - seu anonimato, a frequência com que carros são abandonados e coisas são roubadas ou quebradas, a experiência passada é de "ninguém se importa" - o vandalismo começa muito mais rapidamente do que em Palo Alto, onde as pessoas acreditam que os bens particulares são cuidados e que o comportamento travesso é caro. Mas o vandalismo pode ocorrer em qualquer lugar quando as barreiras comunitárias - o senso de respeito mútuo e as obrigações de civilidade - são reduzidas por ações que parecem sinalizar que "ninguém se importa" (KELLING; WILSON, 1982, n.p., tradução livre).

De acordo com Sousa e Alves (2018), a repercussão do experimento influenciou a política de "Tolerância zero" que se sucedeu na cidade de Nova York, visando a repressão de todo e qualquer tipo de crime. De fato, reduziu-se o índice de criminalidade, entretanto, como ressaltam os autores, houve o aumento do número de encarcerados, uma demanda não esperada pelo Estado. Ou seja, de um lado, o clamor da sociedade por vingança em virtude do mal causado pelo infrator foi alcançado, mas o objetivo principal da penalização, que é a ressocialização do indivíduo, foi posto de lado. De acordo com Odon (2016, p. 2), estudos seguem apontando algumas teorias, como a de haver relação de "causalidade entre desordem e criminalidade, entre a não repressão a pequenos delitos e a criminalidade violenta". Ademais, o estudo realizado por Wilson e Kelling, a partir do experimento de Zimbardo, que relaciona causalidade, desordem e criminalidade na Teoria das Janelas Quebradas ou Broken Windows Theory, verifica que a desordem e o crime possuem uma ligação intrínseca (KELLING; WILSON, 1982).

A exemplificação clássica de tal problemática, surgida através do experimento, suscita sentimento similar com relação ao mobiliário urbano. Uma janela quebrada de uma edificação deve ser rapidamente reparada, preservando, assim, a integralidade do bem, caso contrário "as pessoas que por ali passarem tendem a concluir que ninguém se importa, que não há autoridade zelando pela manutenção da ordem" (ODON, 2016, p. 2). Nota-se que, sobre o mobiliário, frequentemente há a adesão de etiquetas, marcas e riscos provocados por objetos diversos, descarte irregular de gomas de mascar entre outros alimentos e pichações. Uma vez degradado, torna-se menos atrativo, pode comprometer suas funções e corroborar com a atmosfera de um espaço público descuidado e até perigoso. Além disso, a precária manutenção do mobiliário urbano, principalmente em áreas negligenciadas pelo poder público, por si só poderá agir como meio para futuras ações de vandalismo. No entanto, entende-se que, devido à complexidade envolvida nas relações da sociedade atual, esses atos se estendem aos mais diversos espaços 
públicos, independentemente de suas características - como é frequentemente observado no caso dos mobiliários urbanos que têm se tornado mais obsoletos, a exemplo dos telefones públicos, popularmente conhecidos como "orelhões".

Os mobiliários urbanos, assim como outros elementos que localizam-se em espaços públicos, atuam como suporte às atividades cotidianas e propiciam diferentes níveis de interação com os usuários. No entanto, como alerta Montenegro (2013), este contato produz um certo desgaste, o que compromete sua plena atuação quanto ao conforto e à legibilidade, por exemplo. A problemática inerente à supracitada relação evidencia a importância do ordenamento e da funcionalidade do mobiliário urbano, com o prejuízo de tornarem-se ruídos visuais e subutilizados por conta do uso indevido por aqueles que não compreendem a relação objetofunção-ambiente. Assim, sua vandalização e depreciação são resultados da ausência de zelo, visto que esses objetos passam a ser vistos como possíveis obstáculos à circulação dos pedestres, o que acaba levando, consequentemente, à sua degradação, pela inadequação com relação às características do meio (MONTENEGRO, 2013).

As práticas sociais nos espaços públicos e sua relação com a depredação do mobiliário urbano depende de alguns fatores como a observação cautelosa de seu contexto histórico, social e cultural e o esforço coletivo daqueles que, posteriormente, usufruirão de tal infraestrutura. Dessa maneira, as características e peculiaridades da comunidade tendem a ser correspondidas, desenvolvendo "uma relação positiva e memorável entre utilizador e espaço", além da percepção de bem coletivo, inspirando a comunidade a assumir responsabilidades, como "cuidar e proteger, evitando a perda do controlo sobre o estado físico dos espaços públicos e o tipo de comportamentos que neles ocorrem", bem como um enfraquecimento na percepção de conforto e segurança, conforme aponta Cruz (2018, p. 83).

Deve-se notar que, no emaranhado de usos e apropriações diversas evidenciados nos espaços públicos, sobretudo, metropolitanos, o mobiliário urbano pode sinalizar questões mais profundas, não resolvidas no âmbito social. Davis (1993, p. 213) já alertava, por exemplo, que um tipo de banco proposto com a forma de barril para um ponto de ônibus em Los Angeles, Estados Unidos, além de não permitir um sentar confortável, torna impossível que se durma sobre ele. Assim, o objetivo principal desse mobiliário era afugentar sem-tetos e mendigos, e não atender ao cidadão que espera transporte. Décadas mais tarde, esse objetivo parece largamente incorporado em projetos atuais de bancos de muitas cidades, entrecruzando questões complexas de projeto, que ampliam o escopo de funções e significados do mobiliário em tempos atuais, além de suscitar um melhor enquadramento crítico sobre o que se compreende por vandalismo, depredação, uso e conservação do e no espaço público

\section{O design como possibilidade de projeto integrado ao espaço público}

Eventuais soluções para diminuir ou mesmo erradicar atos de vandalismo e depredação ao mobiliário urbano abrange um saber transdisciplinar, em diferentes escalas, desde o design dos espaços públicos - pautado nas especificidades socioculturais do local e de seus usuários -, até 
o design do produto, isto é, as características físicas do mobiliário - como se apresentam e são compreendidos pelos usuários. A junção das duas perspectivas de projeto, nas escalas macro e micro, respectivamente, contribuem para a implementação de um espaço que objetiva oferecer mais qualidade aos cidadãos.

Ao ponderarem a respeito da atenuação de danos causados aos mobiliários urbanos, Faizi et al (2008, p. 16-18) indicam que, para lidar com o vandalismo e diminuir seus efeitos sobre o ambiente, além do conhecimento do contexto social e cultural e suas raízes psicológicas amplamente evidenciados pela literatura especializada -, também é necessário aplicar algumas ferramentas e métodos. Recorrem, portanto, a quatro diferentes metodologias de "urban/environmental design" (desenho urbano/ambiental, tradução livre), complementares: (1) "defensible spaces" (espaços defensivos, tradução livre) e (2) "Crime Prevention through Environmental Design" (CPTED) (Prevenção de crimes através do desenho ambiental, tradução livre), fomentando o projeto de espaços "defensivos", ou seja, espaços facilmente visíveis, já que, em locais com essa característica, as atividades ilegais possuem mais dificuldade de serem concretizadas; (3)"Beautification of Space" (embelezamento do espaço, tradução livre), pois acredita-se que espaços visualmente atrativos diminuem a ação dos vândalos; e (4) "Intensifying participation, possession and responsibility in space" (a intensificação da participação, posse e responsabilidade no espaço, tradução livre).

Somadas, elas anunciam caminhos para a promoção de espaços públicos de qualidade, sustentáveis e resistentes ao vandalismo. Portanto, o design urbano deverá evitar lugares escondidos e/ou fechados; criar usos mistos e ativos; promover o senso de pertencimento ao local; e aumentar a qualidade do meio ambiente, pois, quanto mais um espaço se revela ao sujeito, menor se torna a chance da prática de crimes ou infrações. Além disso, como evidenciado pelo já citado experimento das "Janelas Quebradas", é necessário agilidade na recuperação de estragos provocados por vandalismo, como medida atenuadora de novos danos. Faizi et al. (2008) concluem que uma "linguagem comum do design", ou seja, a participação efetiva das pessoas no desenho do espaço, é um interessante meio para proteção dos espaços públicos, a partir da divisão com os cidadãos de posse, participação e responsabilidades. "A filosofia por trás do uso do design para reduzir o vandalismo é diminuir as oportunidades e capacidades para a ocorrência de crimes" (FAIZI et al., 2008, p.16-17, tradução livre).

Além das estratégias relacionadas ao design ambiental, o design do produto reflete igualmente na maneira que os usuários utilizam e se relacionam com os mobiliários urbanos. Neste contexto específico, para Lobach (2001, p. 159), "visto que a aparência do produto atua positiva ou negativamente sobre o usuário ou sobre o observador, ela provoca um sentimento de aceitação ou rejeição do produto". Portanto, o processo criativo desses elementos perpassa aspectos da percepção "das funções estéticas e simbólicas, sendo um conjunto de informações subjetivas relacionadas diretamente a questões de ordem cultural”, como também indica Montenegro (2013, p. 75).

Montenegro (2013) defende, ainda, a habilidade do mobiliário urbano de tornar os espaços públicos mais convidativos; entretanto, quando deteriorados, interferem na apropriação e na 
percepção dos espaços, causando sua degradação e isolamento. O autor também observa que, à percepção do ambiente urbano, somam-se valores, normas sociais, experiências e memórias próprias. Essa associação ao mobiliário urbano de características ambientais do entorno memória, tradições locais e diversidade cultural - "é condição primordial para que o cidadão se sinta valorizado como parte da estrutura urbana na qual está inserido". O autor, ademais, indica que, no design das peças, é possível manter elementos que "contribuam para a sociabilização do espaço público adequando-se às funções, aos usos e às atividades que ocorrem naquele contexto ambiental", determinando, através de seu conjunto, o espaço urbano (MONTENEGRO, 2013, p. 173).

Como já visto, diversos fatores influenciam o ato de depredação e vandalismo, sendo algo facilmente notado nas grandes cidades. Ghanbari (2017) soma fatores sociais e econômicos à problemática e sugere desde ações especulativas - como criação de contextos sociais e comportamentais motivando a supressão de reações destrutivas, eliminação da injustiça e desigualdade na estrutura dos sistemas sociais e maior responsabilidade e participação social - a ações mais práticas, como melhoria da qualidade do desenho urbano e dos padrões de vida urbana particularmente em zonas mais desfavorecidas, maior vigilância e controle social em locais públicos, além de publicidade e informação através das mídias, objetivando o estabelecimento de relações amistosas no espaço público.

Quanto à sensação de segurança nos espaços públicos, Jacobs (2011, p. 35) já elencava, desde os anos 1960, três características fundamentais para as ruas: nítida separação entre o público e o privado; os olhos para a rua devem estar sempre atentos; e em suas calçadas é necessário um número expressivo e constante de usuários transitando - tanto para aumentar o número de olhos atentos, quanto para induzir um número suficiente de pessoas que, de dentro das próprias edificações, observam as calçadas. Dessa maneira, acredita-se que o que foi presumido pela autora auxilia na redução das práticas de depredação pela cidade, uma vez que a diminuição da criminalidade nos espaços públicos se relaciona a quanto o local é convidativo ao movimento.

O espaço urbano é, de fato, bastante complexo e envolve ações coordenadas em diferentes instâncias. Quanto à materialização de políticas públicas ao enfrentamento dessa delicada questão urbana, tornaram-se gradualmente mais presentes campanhas e ações alertando ou coibindo o vandalismo aos mobiliários urbanos, uma vez que os danos somados pesam nos orçamentos das administrações públicas. Entre as práticas mais recorrentes está atrelar ao próprio mobiliário algum tipo de material publicitário, pois, além de serem os próprios alvos dos delitos, a alternativa apresenta baixo custo e larga veiculação. Outra tática recorrente é a apresentação do custo para substituição de cada peça atrelada ao mobiliário, buscando demonstrar que todos pagam por aquele ato, inclusive os infratores - prática aplicada em diversas cidades espanholas como Los Realejos, Palma, Paterna, Talayuela, Teba, entre outras. Já quando a depredação advém do mau uso dos mobiliários, remodelações em seu design são necessárias, chamando a atenção para sua adequada utilização - como as "bituqueiras" 
instaladas junto a lixeiras públicas em formato de cigarro conscientizando ao correto descarte de "bitucas", em Porto Alegre.

Logo, o design do mobiliário urbano, além de facilitador das boas práticas urbanas, também poderá operar atenuando práticas indesejáveis, especialmente sua própria depredação. Como afirmam Faizi et al (2008), o design do mobiliário é capaz de combater o vandalismo a partir da diminuição de oportunidades para a ocorrência desse tipo de crime. Cruz (2018, p. 83-88) adiciona que, para além da redução de oportunidades, o projeto pode "resistir e até desmotivar o vândalo", ao aumentar os riscos para a realização do ato. Para mais, as soluções devem contemplar os problemas de origem do vandalismo. E, para que tal ação seja exequível, se torna essencial respeitar as normas do design urbano e desenvolver uma boa comunicação entre o espaço público e seu utilizador.

Nesta direção, o design de mobiliário urbano deve associar-se diretamente ao desenho urbano, ao paisagismo, a geografia urbana e cultural, a engenharia urbana, dentre outras, a fim de estabelecer abordagens e conhecimentos que proporcionem a educação voltada prioritariamente à cidadania como forma de pensar e construir coletivamente os espaços públicos da cidade, visando a valorização do cidadão e a melhoria das condições infraestruturais que proporcionem a atratividade, a vitalidade e a sociabilidade no ambiente urbano, resultado do processo de gestão-transformação da urbe (MONTENEGRO, 2013, p. $310)$.

Em pesquisa realizada em dois bairros do Rio de Janeiro (Leblon e Vila Isabel), por ocasião das obras do Projeto Rio Cidade, nos anos 1990, Colchete Filho (1997) já havia destacado que os usuários das áreas se sentiam mais valorizados quando identificavam um espaço público bem cuidado, com manutenção periódica e a presença de mobiliário urbano em quantidade e qualidade suficientes. Entretanto, o oposto também era verdadeiro. Quando se lembravam de lugares abandonados, com a ausência de mobiliários, imediatamente relacionavam o fato à ausência do poder público no espaço urbano. Mobiliário urbano e espaço público certamente dão uma ideia da concepção que o cidadão pode ter de democracia e de cidadania em cada contexto e lugar.

Outra pesquisa, realizada por Rocha (2005), relacionou diretamente o estado de conservação de mobiliários urbanos com os atos de vandalismo. O autor analisou as condições físicas de abrigos de ônibus em três cidades - Curitiba, Rio de Janeiro e São Paulo -, o que o levou a apontar o vandalismo como uma consequência advinda da falência dos espaços públicos, sobretudo em zonas periféricas ou carentes, onde existe uma "deficiência funcional" latente dos equipamentos, além da falta de clareza a respeito das reais necessidades dos usuários e sua ocupação por pessoas em situação de rua.

Em suma, torna-se possível perceber que um bom design urbano, aliado a um bom design do mobiliário, são ações que, quando somadas, influem diretamente na percepção do indivíduo sobre o espaço. E essa percepção, quando majoritariamente positiva, pode contribuir com a diminuição do vandalismo sobre o mobiliário urbano, uma vez que o usuário cria vínculos de pertencimento com o espaço público em questão, o que permite pensar no design como processo constitutivo do mobiliário urbano e de sua influência na mitigação, ou mesmo produção de atos 
de vandalismo. Ademais, nota-se que a preocupação do poder público em conter tais atos se traduz em métodos que, de alguma maneira, corroboram a perspectiva abordada por este estudo: as respostas positivas ou negativas dos usuários aos estímulos lançados pelo mobiliário urbano estão diretamente atreladas à sua melhor inserção nos espaços públicos de forma eficiente e, também, inclusiva socialmente.

Figura 1 - Matriz de complexidades em projetos de mobiliários urbanos sensíveis ao lugar.

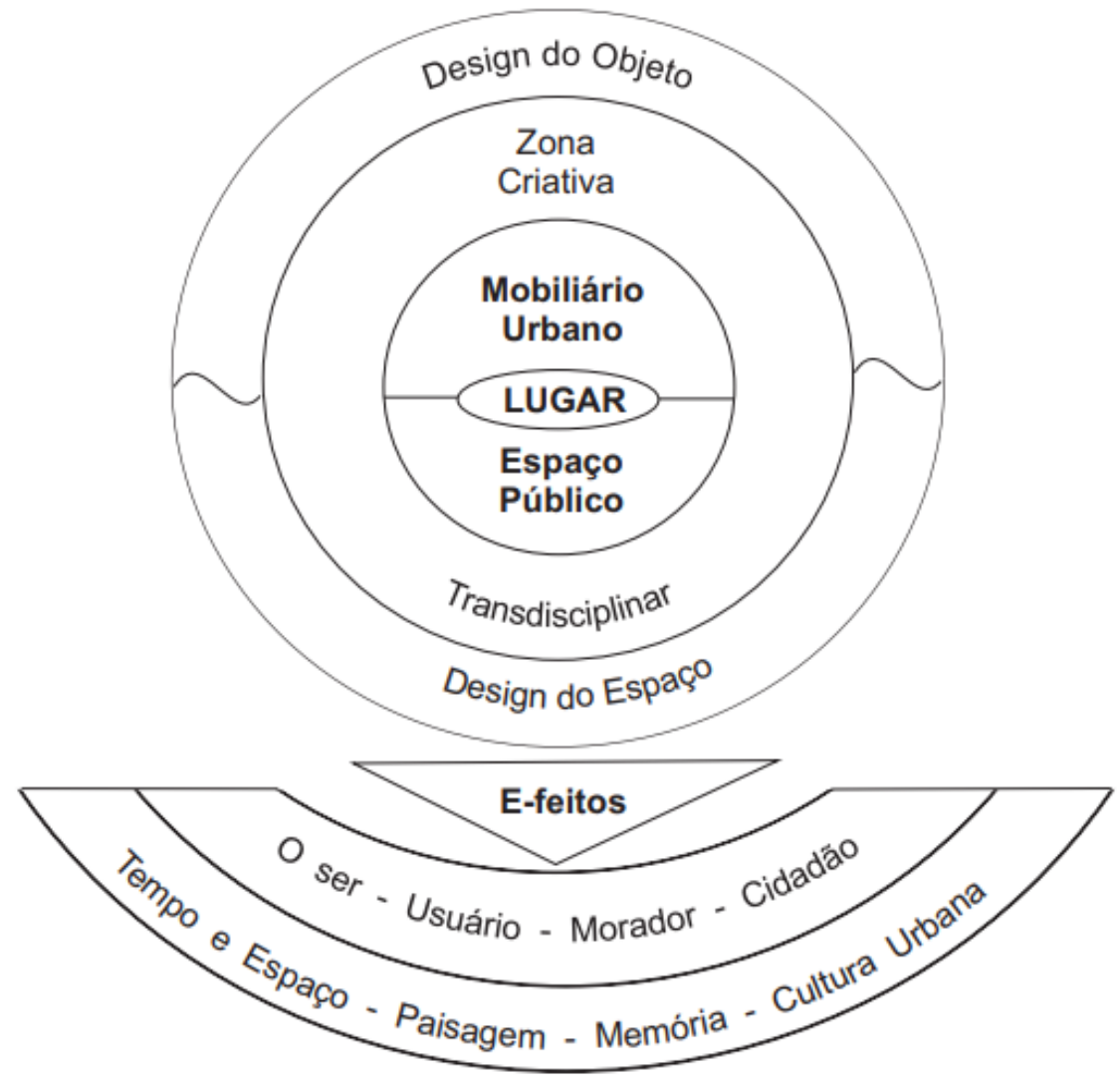

Fonte: Os autores (2021).

Com base nos referenciais teóricos do presente estudo, o Quadro 1 sintetiza alguns pontos para discussão. A premissa é considerar que o mobiliário urbano e o espaço público são partes da discussão central sobre a ideia de lugar. O design do objeto (mobiliário urbano) e o design do espaço (lugar) trazem resultados mais efetivos, quando integrados em uma prática criativa de caráter transdisciplinar, isto é, incorporam criticamente demandas e saberes de diferentes campos e experiências acumuladas historicamente, nos âmbitos técnico, econômico, cultural etc. Afirma-se, assim, que os efeitos pretendidos e alcançados são sensíveis ao ser, caracterizado no papel mais simples, como usuário, daquele objeto-espaço, mas que também carrega afetos, como morador, e expectativas, como cidadão. Esse conjunto possível de diferentes "e-feitos" pode ser cada vez mais avaliado nas mídias sociais, como a grafia acentua. Paisagem, memória e cultura são, portanto, mais do que instâncias espaciais para recepção dessa inter-relação, são atributos potentes para inscrição sensível de subjetividades coletivas. 
Assim, soma-se à observação da natureza primordial da ação do design fatores importantes, como a problemática do custo social do vandalismo e da inclusão social por meio do mobiliário. Cada mobiliário urbano existente, projetado ou alterado deve ser compreendido com sua relação de interdependência com o lugar onde se instala e sua comunidade. O mobiliário urbano deve motivar aproximação entre os sujeitos e os espaços públicos - peças-chave também para o fortalecimento de identidades em cada lugar e para a contínua formação de memórias urbanas, em prol de uma vivência mais pacífica, democrática e plena de urbanidade.

\section{Considerações finais}

O mobiliário urbano, bem como as relações propostas aos seus usuários, denotam formas de se compreender e apreender os espaços públicos no curso da história. Por conta de suas mutações, há mobiliários que se tornaram obsoletos, com a introdução de novas tecnologias ou necessidades, e os outros que estão constantemente em processo de reinvenção e adaptação. Há os que são essencialmente funcionais, em contrapartida daqueles que propõem novas conexões e abordagens do indivíduo com o espaço público. Por isso, deve-se atentar para a produção de mobiliários urbanos que correspondam às necessidades do ambiente onde será inserido, a fim de que sua função, no sentido mais amplo que esse termo comporta, seja exercida com êxito. $\mathrm{O}$ design é certamente um campo disciplinar fecundo para a adoção de métodos e práticas que contribuam para que as interfaces com os indivíduos sejam ampliadas, como parte integrante e fundamental na preservação do espaço público e dos mobiliários urbanos, nele dispostos. $\mathrm{O}$ efetivo exercício com outros campos disciplinares, como a arquitetura, engenharia e gestão urbanas, podem revelar experiências bem-sucedidas.

A literatura e até o senso comum apontam que áreas urbanas sem manutenção e vigilância constantes ou eficientes são mais suscetíveis a atos de vandalismo. Além disso, a depredação intencional está altamente relacionada à percepção do indivíduo sobre os objetos. Dessa maneira, torna-se evidente o quanto a qualidade do mobiliário pode repercutir na própria qualidade e leitura do espaço público. Nesse sentido, identifica-se também a importância que recai sobre os usuários e aos responsáveis pelo projeto de tais elementos, sendo necessária, cada vez mais, a busca por soluções criativas e sustentáveis na valorização do meio urbano através de seus mobiliários.

No âmbito do projeto, considera-se de extrema relevância a ponderação das questões relacionadas ao vandalismo, posto que, nessa etapa, podem ser desenvolvidas soluções que minimizem a ocorrência desses atos, desde a prototipagem do produto e da sua inserção em fase de teste no espaço público. Pontua-se, assim, a abordagem do tema junto à sociedade em diferentes fases do processo, ampliando práticas participativas que muito podem agregar ao resultado final. O desenvolvimento de materiais divertidos, lúdicos, que chamem positivamente a atenção para o mobiliário, tem se mostrado mais eficiente, além de promover efetivamente a melhor integração com os usuários, conscientizando-os para a preservação de um bem comum, e, sobretudo, do entendimento de que a conta por seus danos é dividida entre todos. 
Por fim, ressalta-se a estreita relação existente entre conflitos sociais e a depredação dos espaços públicos, especialmente dos mobiliários urbanos. Neste contexto, o design surge como uma possibilidade projetual de integração efetiva das comunidades junto a seus espaços públicos, através de uma série de diretrizes que abarcam a funcionalidade intrínseca a estes elementos urbanos e a racionalização dos processos de sua constituição, além dos estímulos particulares que o mobiliário e a sua configuração no espaço são capazes de produzir nos usuários diretos de um lugar e no legado que representam para a qualidade dos espaços públicos e da paisagem.

\section{Agradecimentos}

$\mathrm{CNPq}$ - Conselho Nacional de Desenvolvimento Científico e Tecnológico

CAPES - Coordenação de Aperfeiçoamento de Pessoal de Nível Superior

\section{Referências}

BOSTANI, Maryam Karimian; SADEGUI, Mohsen; AGHAI, Aliakbar. The impact of the juvenile vandalism in the public urban space: the case of Parsabad's city in Iran. Espacio Abierto Cuaderno Venezolano de Sociología, v. 26, n. 4, 2017.

BRASIL. Decreto - lei $\mathrm{n}^{\text {o }} 2.848 / 40$, de 7 de dezembro de 1940. Disponível em http://www.planalto.gov.br/ccivil_03/decreto-lei/del2848.htm Acesso em 12 de dezembro de 2019

COHEN, Stanley. Sociological approaches to vandalism. In: LEVY-LEBOYER, Claude. Vandalism: Behavior and Motivations. Nova York: Elsevier Science Publishers B. V. 1984. p. 231-233.

COLCHETE FILHO, Antonio Ferreira. Estudo sobre o mobiliário urbano no Rio de Janeiro: a experiência do Projeto Rio Cidade Leblon e Vila Isabel. 1997. Dissertação (Mestrado em Urbanismo) - Universidade Federal do Rio de Janeiro, Rio de Janeiro, 1997.

CORREIA, Victor. O Vandalismo da Arte Pública. Convocarte, Lisboa, n. 1, p. 77-89, 2015.

CREUS, Marius Quintana. Espacios, Muebles y Elementos Urbanos. In: SERRA, Josep Maria. (org) Elementos Urbanos: Mobiliario y Microarquitectura. Barcelona: Gustavo Gili. 1996. p. 6-14.

CRUZ, Maria João Correia. Design urbano e o vandalismo no espaço público: a intervenção do Indivíduo no espaço público. 2018. 101f. Dissertação (Mestrado em Design de Equipamento) - Universidade de Lisboa, Lisboa, 2018.

DAVIS, Mike. Cidade de quartzo: escavando o futuro em Los Angeles. São Paulo: Scritta Editorial, 1993.

FAIZI, Mohsen; HOSSEINI, Seyed-Bagher; ASL, Sina Razzaghi. Identification of environmental design methods and techniques for preventing vandalism. Environmental Sciences, v. 6, n. 1, 2008.

JACOBS, Jane. Morte e vida de grandes cidades. $3^{\text {a }}$ ed. São Paulo: Editora WMF Martins Fontes, 2000. 532p. 
KELLING, George Lee; WILSON, James Quinn. Broken Windows, the police and neighborhood safety, Revista "The Atlantic". Março de 1982. Disponível em: https://www.theatlantic.com/magazine/archive/1982/03/broken-windows/304465/ Acesso em 27 de julho de 2020.

LOBACH, Berndt. Design Industrial - Bases para a configuração de produtos industriais. São Paulo: Editora Edgard Blucher, 2001.

MONTENEGRO, Glielson. Uma cidade para pessoas: Funcionalidade, racionalidade e emotividade nas relações mobiliário urbano, espaço público e cidadãos. 2013, 348f. Tese (Doutorado em Arquitetura e Urbanismo) - Universidade Federal do Rio Grande do Norte, Natal, 2013.

MOSER, Gabriel. What is Vandalism? In: ROOS, Hans-Edvard. Vandalism as a Symbolic Act in Free Zones, Seattle: US Dept. of Agriculture / Pacific Northwest Research Station and University of Washington. 1992. p. 49-59.

MOSER, Gabriel. Psicologia Ambiental. Estudos de Psicologia, 3(1), p. 121-130, 1998.

ODON, Tiago Ivo. Tolerância Zero e Janelas Quebradas: sobre os riscos de se importar teorias políticas. Textos para discussão. Núcleo de Estudos e Pesquisas/CONLEG/Senado, Brasília, 194, 2016.

ROCHA, Luís Fernando Campanella. Gestão pública do mobiliário urbano. Oculum Ensaios, Campinas, n. 3, p. 111-121, 2005.

SOUSA, Cássio dos Reis Lopes; ALVES, Fernanda do Carmo Rodrigues. A teoria das janelas quebradas aplicada na atualidade. Biblioteca digital de segurança pública, 2018. Disponível em: https://acervodigital.ssp.go.gov.br/pmgo/bitstream/123456789/1449/1/978986670678_C\%c3\%a1ssio_Dos_Reis_Lopes_De_Sousa_Deposito_final_13447_1493989527.pdf Acesso em 27 de julho de 2020.

\section{Sobre os autores}

\section{Fernando Araújo Costa}

Arquiteto e Urbanista (UFJF), mestrando em Ambiente Construído (PROAC/UFRJ) e pesquisador no grupo de pesquisa ÁGORA/CNPq.

https://orcid.org/0000-0003-4329-2229

\section{Karine Dias de Jesus}

Arquiteta e Urbanista (UFJF), mestra em Ambiente Construído (PROAC/UFRJ) e pesquisadora no grupo de pesquisa ÁGORA/CNPq. https://orcid.org/0000-0003-2899-7116

\section{Antonio Ferreira Colchete Filho}

Arquiteto e Urbanista (UFRJ), Doutor em Ciências Sociais (PPCIS/UERJ). Professor Titular no Programa de Pós-graduação em Ambiente Construído (PROAC/UFRJ). Líder do Grupo de Pesquisa ÁGORA/CNPq. Bolsista de Produtividade em Pesquisa do CNPq - Nível 2.

https://orcid.org/0000-0003-4776-123X 